http://dx.doi.org/10.1590/0104-07072017006050015

\title{
VIOLATIONS OF NURSES IN THE USE OF EQUIPMENT IN INTENSIVE CARE
}

\author{
Gabriella da Silva Rangel Ribeiro ${ }^{1}$, Rafael Celestino da Silva², Márcia \\ de Assunção Ferreira ${ }^{3}$, Grazielle Rezende da Silva ${ }^{4}$
}

${ }^{1}$ Nurse. Member of the Núcleo de Pesquisa de Fundamentos do Cuidado de Enfermagem. Escola de Enfermagem Anna Nery (EEAN),
Universidade Federal do Rio de Janeiro(UFRJ). Rio de Janeiro, Rio de Janeiro, Brazil. E-mail: gabrielaasrr@hotmail.com
${ }^{2}$ Ph. D. in Nursing. Professor, Department of Basic Nursing, EEAN/UFRJ. Rio de Janeiro, Rio de Janeiro, Brazil. E-mail: rafaenfer@
yahoo.com.br
${ }^{3}$ Ph. D. in Nursing. Professor, Department of Basic Nursing, EEAN/UFRJ. Researcher at CNPQ. Rio de Janeiro, Rio de Janeiro,
Brazil. E-mail: marcia.eean@gmail.com
${ }_{4}^{4}$ Master's student. EEAN/UFRJ. Rio de Janeiro, Rio de Janeiro, Brazil. E-mail: graziellerezende@gmail.com

ABSTRACT

Objective: to identify situations of violation in the use of equipment by nurses in the intensive care unit and analyze their implications on patient safety.

Method: a descriptive field study with qualitative approach was carried out from March to December 2014, with the use of James Reason's violation concept. The participants were nurses from the day shift, working in direct care at an intensive care unit of a federal hospital. Data production was carried out through systematic observation and interviews, and were analyzed based on thick description of scenes and content of responses.

Results: violations in planning care regarding the checking of the equipment functioning before its use and alarms were found, when nurses disconnect them to reduce the effects caused by the overload of noise on the team.

Conclusion: the situations reported compromise safety and cause serious risks to patients. Therefore, implementation of strategies to promote a safety culture is required.

DESCRIPTORS: Nursing. Patient Safety. Biomedical Technology. Critical Care. Medical Errors.

\section{VIOLAÇÕES NO USO DE EQUIPAMENTOS POR ENFERMEIROS NA TERAPIA INTENSIVA}

\section{RESUMO}

Objetivo: identificar situações de violação no uso de equipamentos por enfermeiros na unidade de terapia intensiva e analisar suas implicações quanto à segurança do paciente.

Método: pesquisa de campo, descritiva, com abordagem qualitativa, realizada de março a dezembro de 2014, com aplicação do conceito de violação de James Reason. Os participantes foram enfermeiros do período diurno, atuantes na assistência direta na Unidade de Terapia Intensiva de um hospital federal. A produção dos dados se deu através da observação sistemática e entrevistas, analisados com base na descrição densa das cenas e no conteúdo das respostas.

Resultados: há violações do planejamento da assistência quanto à verificação do funcionamento do equipamento prévio a sua utilização e quanto aos alarmes, quando as enfermeiras os desligam para atenuar os efeitos da sobrecarga sonora sobre a equipe.

Conclusão: as situações registradas comprometem a segurança e causam sérios riscos aos pacientes, sendo necessário aplicar estratégias que promovam uma cultura de segurança.

DESCRITORES: Enfermagem. Segurança do paciente. Tecnologia biomédica. Terapia intensiva. Erros médicos. 


\title{
VIOLACIONES EN EL USO DE EQUIPO POR LAS ENFERMERAS EN LA UNIDAD DE TERAPIA INTENSIVA
}

\begin{abstract}
RESUMEN
Objetivo: identificar situaciones de violación en la utilización de equipos por enfermeros en la unidad de terapia intensiva; y analizar sus implicaciones en la seguridad del paciente.

Método: investigación de campo, descriptiva, con abordaje cualitativo, realizada de marzo a diciembre de 2014, con aplicación del concepto de violación de James Reason. Los participantes fueron enfermeros del período diurno, actuantes en la atención directa en la Unidad de Terapia Intensiva de un hospital federal. La producción de datos ocurrió a través de la observación sistemática y de entrevistas, analizados con base en la descripción densa de las escenas y en el contenido de las respuestas.

Resultados: hay violaciones de la planificación de la asistencia cuanto a la verificación del funcionamiento del equipo previo a su utilización; y cuanto a los alarmes, cuando las enfermeras los desligan para atenuar los efectos de la sobrecarga sonora sobre la equipe.

Conclusión: las situaciones registradas comprometen la seguridad y causan serios riesgos a los pacientes, siendo necesario aplicar estrategias que promuevan la cultura de seguridad.
\end{abstract}

DESCRIPTORES: Enfermería; Seguridad del paciente; Tecnología Biomédica; Cuidados intensivos; Errores médicos.

\section{INTRODUCTION}

Patient safety in the healthcare context is considered a priority theme in the current worldwide agenda, due to economic and social costs resulting from the occurrence of adverse events, such as those caused by medication errors and lack of hand hygiene. Therefore, safe care is a challenge, which requires new studies in the scientific field that seek to measure errors, understand the causes of adverse events, and propose intervention measures to promote safety. ${ }^{1}$

Regarding this matter, it is worth mentioning Edict No. 529 of April 1, 2013 that launched the National Patient Safety Program (PNSP, as per its acronym in Portuguese). ${ }^{2}$ One of its focus is the use of technologies, due to their incorporation's risks to health care. Technology in health refers to "medications, technical equipment and procedures, organizational, informational, educational, and support systems, and assistance programs and protocols through which care and health care are provided to the population". 3:30

Therefore, in the present study, the use of the term technology is associated with the equipment used in critical care. In this respect, a significant increase was found in the number of incidents associated with the handling of this equipment. Many of the incidents reported with defibrillators, infusion pumps, and mechanical ventilators are associated with the equipment's user. - $^{4}$

A review of obligatory notifications of incidents associated with medical equipment in France in 1998 showed $11 \%$ of severe incidents and $2 \%$ of fatal incidents. ${ }^{4}$ Alarms were in the list of the ten highest risks in 2014 with technologies, ${ }^{7}$ however, infusion pumps accounted for about $30 \%$ to $60 \%$ of the incidents with intravenous medication. ${ }^{5}$
Regarding consequences for patients, the case of a specific defibrillator model is mentioned, in which after every synchronized attempt to cardioversion, it returned to its non-synchronization standard mode. However, after an unsuccessful attempt to cardioversion, the device's user did not notice that the synchronization disappeared from the monitor and inadvertently carried out a defibrillation, thus causing ventricular fibrillation. ${ }^{8}$

The analysis of this situation shows that one of the factors leading to the occurrence of these incidents with equipment is violation by professionals. Violations have been mentioned as a cause of incidents in intensive care units (ICUs) in a high rate, becoming as relevant as the matter of knowledge and experience. Not checking equipment before anesthesia and disconnecting alarms are common practice. ${ }^{4}$

Furthermore, alarms are a critical issue in the context of violations, especially when they are disconnected and a cardiac complication is undetected; or when a central monitoring system does not trigger the alarm during the development of a cardiac arrest in a patient, and the bed's alarm that was set in its minimum volume is not heard. ${ }^{5}$

In addition to endangering patients' lives, this problem also brings financial implications, since the number of legal actions filed by patients who seek compensatory damages is high. Therefore, managing risks from using equipment is essential, with a focus on factors that intervene with safety, such as violations.

Violations are considered deliberate deviations of rules, routines, recommendations, and safe operational procedures. They are chosen actions that generate risks when distanced from what is prescribed in standards. Although intentional, they do not mean to cause damages, but only "shorten" the path to undertake an activity, which ends up deviating the action from the expected course. This 
concept integrates the human error theory proposed by James Reason in 1990, which aims at understanding mechanisms that would explain errors, so that measures can be adopted for their prevention, as well as their detection/correction. ${ }^{9-10}$

The distinction between the concept of error and violation is used in this theory to understand processes that operate in the event of errors, aiming at guiding the establishment of defensive measures with a focus on safety improvement. Errors are justified by human fallibility and violations by culture and behavior, thus requiring different measures. Understanding violations is essential, since it might be the beginning of a process that progresses to errors. ${ }^{9-10}$

There is a nursing care practice in ICU, ${ }^{11}$ in which diverse techniques, technologies, and specialized knowledge modulate interaction and exert influence in the undertaking of care activities by nurses to critically ill patients. ${ }^{11}$

Studies show evidence of ambivalence attitude from nursing teams in ICUs regarding equipment. ${ }^{4,12}$ One of these ambivalences is due to high confidence levels of experienced operators in automation, which might lead to the inappropriate monitoring of the equipment. Evidence suggests that ICU nurses have a potential to show complacent behaviors, with real possibilities of damages to patients due to this confidence. ${ }^{12}$

Therefore, the aim of the study was to identify situations of violation in the use of equipment by nurses in the intensive care unit and analyze their implications on patient safety.

\section{METHOD}

A descriptive field study with a qualitative approach was carried out in an ICU of a federal teaching hospital located in the city of Rio de Janeiro. The study was approved by the research ethics committee of the abovementioned hospital, under protocol No. 260.345/13, CAAE 15619913.5.0000.5238, in compliance with Resolution No. 466/2012 of the Brazilian National Health Council. After approval, field researchers were included to be familiarized with the reality of the study, approach potential participants for presentation of the research's proposal, and later, invite them to participate in the study. Those who accepted signed an informed consent form and were identified according to the order of data production.

The ICU has an area for clinical patients with nine beds, with a nursing team per shift made up of two nurses, and a surgical area with six beds and one nurse per shift. Both take turns in a scale of 12 working hours with 60 hours of rest. Nine nurses work in the day shift and nine in the night shift.

The inclusion criteria were: being an ICU nurse providing direct care to patients in the day shift; working in the sector during the period intended to the study. The sample was made up of eight nurses, because one nurse was not working during the period of the study. The study was carried out during the day shift because most direct care provided to patients and diagnostic procedures occur during the day, offering better conditions to learn the work behaviors of nurses in attendance to the objectives of this study.

Data production occurred from March to December 2014, by means of a systematic observation technique applied to learn how nurses acted regarding the use of equipment in patient care. The observation script was organized in two parts. The first was the characterization of the observation scene, containing data such as date and time of observation, type of situation observed, clinical information of the patient who was in the scene observed, and professional observed. Initially, data of the professionals' characteristics were collected, such as education, qualification, and practice field, to associate them with their care practice.

The other part of the instrument was developed based on the literature that showed the equipment involved in incidents and associated factors. ${ }^{4-6,13}$ Based on this, it was chosen to observe situations focused on the practice of nurses in the handling of equipment for monitoring hemodynamic parameters, infusion of solutions and nutrients, and ventilation. The instrument included information on: data configuration by professionals, interpretation of the meanings of actions/commands; ability to detect/solve problems; handling of alarms; difficulties in handling; and interruptions.

The observation of the use of equipment was carried out during daily care scenes to meet biological needs, admission and transference of patients in the sector, undertaking of high complexity procedures and techniques, performance at times of clinical complications, and clinical meeting of the nursing team, with a total of 130 hours of observation.

The records of observations were carried out in a field diary with the following categorization: theoretical, methodological, and personal notes. Notes of scenes and care practices were deeply undertaken, based on principles of thick description, which comprises the description of scenes and interpretation of the researcher and the researched. 
Types of violation, associated factors, behaviors, and damages to patients were recorded, and later, nurses involved in the scenes recorded were questioned, with the aim of understanding the meaning of their behavior and perspectives on the situations identified.

The participants' responses were recorded and transcribed in the field diary, and analysis of their content was used in the whole of the analysis of scenes as support for interpretation of the results.

The results were organized in two categories, which represented the highest occurrences recorded in the scenes observed: battery charging of the equipment and clinical alarms. The analysis considered the following classification of violation highlighted by Reason: routine violations - they occur in the course of daily activities and are characterized by the use of shortcuts to undertake these tasks; necessary violations - they occur when the violation of the rule is the only way to undertake the task; and violations to increase effectiveness - they occur with the purpose of achieving personal gain. ${ }^{9-10}$

\section{RESULTS}

\section{Violation of equipment's battery charging}

This violation is associated with ways of acting adopted by the team, marked by deviations of the practice recommended for equipment's battery charging, which generate repercussions in the appropriate functioning of these devices. In turn, this impacts on the result expected of their use in patients, with potential undesired effects on them.

Situations when these deviations emerge are reported in comments of nurses: The most common problems are batteries that are not charged [...] (Nurse 6); Hey, the transport is worse! The other day, I was transporting a patient and the monitor turned off due to lack of battery. In addition, he was a very unbalanced patient who was undergoing a computer tomography. Hey, it was difficult! These batteries are a problem, you will see in your shift, it happens all the time, but it should not [...] (Nurse 1); I have already had problems with monitors [...] the battery ran out in the middle of the transport. We were returning from a computer tomography, he was a patient with hypertensive peaks, but not so serious. As we were already in our way back, we did it as fast as possible, and we checked everything when we arrived. He did not have any problems, but I was very nervous! (Nurse 8).

The nurses interviewed indicate the violation of planning for the use of equipment, especially regarding the effects from lack of battery during the transport of critically ill patients. In practice, during the observation of situations where the transport of patients was required, this violation of the preparation of equipment is ratified.

It is what happens when Nurse 1 prepares the patient of bed 14 for his transference to the clinical sector in the morning. She goes to the store unit in search for an infusion pump. When initiating its functioning, she notices that it has no battery. She returns to the store unit and chooses another infusion pump with the same problem. She is able to pick up a device that is working only in the third attempt, which leads her to mention this situation to Nurse 3.

The staff has to put the pumps to be charged, I picked up two there, but they were not charged. Nurse 3 says: let us report this in the change of shifts, there is no other way! (extract from the field diary, Nurses 1 and 3, 7:30 a.m.-12:10 p.m.).

Consequences from not charging batteries were seen on the day when Nurses 1 and 4 were evaluating two patients at the nursing station, who required transport for the undertaking of examinations, being one for endoscopy and the other for abdominal computer tomography. Both were scheduled for the same time; however, close to the scheduled time, there was only one transport monitor charged in the sector. In the attempt to solve such problem, Nurse 1 went to the clinical ward to pick up another monitor that had been used during a previous transference of an ICU's patient to this ward (extract from the field diary, Nurses 1 and 4, 1:00 p.m.-5:00 p.m.).

\section{Violation of clinical alarms}

One of the violations that often occurs in the daily care of an ICU refers to behaviors of nurses with regard to clinical alarms. Therefore, the analysis of such behaviors enables the understanding of the following violations' characteristics: disconnection, reduction of volume, late response, and absence of response.

The comment of Nurse 5, based on the observation by the researcher of a scene of hygiene on the bed, in which the alarm was disconnected, explains this behavior: Alarms are very important, but sometimes they are very annoying. They trigger for no reason when devices start breaking, and then, we have to disconnect the alarm or reduce its volume. However, it is amazing how much we need them to work (Nurse 5); They trigger for any reason [pumps], sometimes, there is nothing wrong and they trigger. However, they are important because sometimes, something is really happening [...] or the 
medication is finishing, but there is something wrong with the circuit and we need the alarms. What you cannot do is disconnect or forget to program them properly as it happened today (Nurse 6).

In contrast, field records show that disconnections not always occur because of equipment malfunction, but because of the deliberate deviation of professionals, especially when they are close to patients, evaluating or providing them with specific care, such as bath. However, this results in forgetfulness, and when nurses are distant from patients to undertake other activities, the detection of clinical events becomes difficult, thus delaying the adoption of intervention measures.

Descriptions of hygiene scenes illustrate this statement, like in the two cases presented as follows. The first involves a 58-year-old patient hospitalized in bed 6 with medical diagnosis of sickle cell anemia and chronic renal insufficiency, under continuous use of macro-nebulization due to dyspnea. At the beginning of the procedure, the monitoring equipment was disconnected and, after the procedure, it was reconnected to the patient, showing increase in respiratory rate, blood pressure $(170 \times 100 \mathrm{mmHg})$, and drop in oxygen saturation in arterial blood ( $\mathrm{SaO} 2-85 \%)$.

The device's alarm triggered and Nurse 8 turned it off. It remained disconnected for approximately 30 minutes, during which dressings were applied. When Nurse 6 was leaving the bed, the researcher reminded her about the alarm, and she answered: I am glad you reminded me, because these alarms are too much. I sometimes turn them off when I am with the patient, but then, I forget to activate them (extract from the field diary, Nurses 1 and 3, 7:30 a.m.-11:20 a.m.).

Questioned about the disconnection, she continued: it did not happen with me, but I was passing by the surgical ICU and a patient was with extremely low heart rate, very hypotensive, and nobody noticed this because the alarm was off [...] I activated the alarm, we called the medical team and gave him Noradrenaline. If I had not seen, the patient's heart might have stopped and we would not see. Later, he even had a cardiac arrest, but we were attentive to signs and alarms, and we were able to revert his condition.

In the second situation, the researcher who arrived at the scene of the study identified that the monitor of bed 12 was displaying a light signal to alert alterations in blood pressure levels $(210 \times 110$ $\mathrm{mmHg}$ ). The alarm's volume was very low, whose sound was also hampered by the noise of the unit's mechanical ventilators. After detecting it, the researcher communicated the fact to Nurse 6, who went to this bed, reconfigured the alarms, and after that, searched for the medical team to report the episode and discuss about the therapeutic conduct to be applied. When she came back, Nurse 6 said to the researcher: we forgot to increase the alarms' volume after the bath, I am glad you warned us! (extract from the field diary, Nurse 6, 1:00 p.m.-5:30 p.m.).

Considering that the episode was identified at 1:00 p.m. and baths are given from 9:00 a.m. to 11:00 a.m., it is not possible to identify for how long the patient remained with the parameter altered. This example shows the non-detention of a cardiac incident with the patient, due to the violation through the reduction of the alarm's volume. This delay in the identification of the event might lead to repercussions that compromise the patient's life, as seen as follows.

At 10:30 a.m., Nurse 6 and a nursing technician were at the nursing station, when another nursing technician of the team passed by the unit in a hurry and informed that the mechanical ventilation circuit of patient from Box 10 was detached from the tracheostomy. Everybody ran toward this bed, and when they arrived, they noticed that the patient had signals of cyanosis by the color of extremities and face. The patient evolved with blood pressure of 180 $x 110 \mathrm{mmHg}$ and SaO2-79\%. Nurse 6 reprogrammed the alarm, and after the occurrence, she comments about the episode:

[...] in our routine, whoever receives the patient has to program devices and alarms according to their needs. I have never had problems with alarms of ventilators. They are the noisiest. This alarm was not properly programmed, as well as others that I have just finished updating. The staff from the night shift likes to reduce the alarms' volume, or somebody did not check them. (extract from the field diary, Nurse 6, 7:30 a.m.-12:00 p.m.).

\section{DISCUSSION}

The use of equipment in the care of critically ill patients by nurses and its appropriate handling is worrying in situations of transport, since scenes and statements described show the existence of violations in planning regarding the prior inspection and check on the functioning of these devices before their use.

As a result, situations of malfunction of devices that compromise patient safety and might cause them damages are recorded, which include: non-infusion of medications through the use of infusion pumps; inappropriate oxygenation through the use of ventilation devices; and non-identification of a clinical 
alteration with consequent delay of interventions, as mentioned by Nurses 1 and 8 in their statements.

This issue on incidents with equipment is also highlighted in other studies, ${ }^{6,14-15}$ such as a study that discussed the type of problems with machines, which is worth knowing. This study shows that inappropriate use is the main cause of incidents associated with equipment in ICUs; however, the nature of such incidents is multifactorial. Failures that occur with devices are an example of this, which are both associated with obsolescence and inappropriate maintenance, and lack of control before their use. Therefore, prior checking on the proper functioning of devices is a strategy to promote patient safety and, conversely, its violation increases the risk of incidentes. ${ }^{6}$

These incidents may be observed in a literature review that tracked complications presented by critically ill patients during intra-hospital transport. An adverse event that stood out was a problem of the multidisciplinary team, whose cause was the lack of knowledge and inappropriate communication. Errors based on knowledge corresponded to 54\% of the incidents. Error in preparing the equipment is among them; equipment failures, which were categorized according to the equipment's modality as follows: ventilation (disconnection, empty cylinders, bags with inappropriate seal); infusion (end of battery; end of medication); monitoring (malfunction, end of battery, interference, malfunction of the arterial line). It is thus concluded that the abovementioned errors were committed by the team, which are situations that could be prevented. ${ }^{14}$

This type of violation evidenced in the data and corroborated by the support literature is called routine violations according to Reason, which often occur in an attempt to gain time or with the intention of being available as quickly as possible to undertake a more urgent activity. It crosses simple and more complex procedures. ${ }^{9}$

It is worth mentioning that this use of rules, standards, and guidelines in the safety field aims at preventing damages to patients; however, in the health area, there is a high rate of violation of important standards, such as the case of hand hygiene. Low adherence to hand hygiene is a phenomenon that represents the most common example of violation against prescribed standards. Studies have also shown this low adherence in critical care. ${ }^{16-17}$ When identifying the adherence of healthcare professionals of an ICU to the five moments for hand hygiene, researchers found an adherence rate of $43.7 \%$, with absence of hand hygiene in 446 observations
(56.2\%). The nursing technicians' category had the lowest adherence. ${ }^{16}$

In the specific case of the use of equipment in ICUs, a planning phase is required so that this is safely done, which involves the preparation of the equipment regarding the autonomy of batteries, as well as checking for any malfunction. However, the data show the violation of this planning, with a potential to cause damages to patients.

This behavior of the team may be explained by the characteristic of the work environment, marked by the urgency of situations. This is because care provided in ICUs is focused on a profile of patients with instability of organic systems' functions, which results in imminent situations of emergency, continuous alertness, and multiple invasive procedures.

As a result, such routine violation becomes tolerable for the supervision. Influence in the supervision of the practice of other members of the team is a factor observed in the data, especially when Nurse 1 says: It happens all the time, but it should not. Communication and coordination skills are aspects that are associated with supervision and might contribute to unsafe actions. ${ }^{18}$

Regarding communication, its importance as a part of the supervision of members of the team concerning the planning for the use of equipment in the ICU is highlighted in the empirical data by Nurse 3, who expresses her concern about the noncharging of batteries of infusion pumps, and the need for dialogue with other colleagues to sensitize them on the relevance of this activity. This scene illustrates the effects of the communication process among all of those involved in the ICU in the good performance of their work, exchange of knowledge, and consequently, the recovery of patients.

However, communication failures between supervision and team about the situation of equipment during the exchange of shifts and the checking of devices during the work process might have generated the situation involving Nurses 1 and 4, in which no single device was available to transport a critically ill patient.

This result can be contrasted with other communication failures in ICUs discussed in studies, such as the case of the handover. Handover refers to the transmission of relevant information for the continuity of patients' treatment to another professional team in the course of the care provided, during admission and hospital discharge. Studies point out that approximately $70 \%$ of errors and adverse events occur due to communication failures. Among these, almost half occurred during handover among 
healthcare professionals, caused by omissions of critical information about patients and their care plan. ${ }^{99-20}$

Therefore, the team must be attentive to interactive work, contributing to interdisciplinary knowledge and facilitating the communication process to prevent incidents. For this purpose, communication skills in ICUs are required, making it possible to organize, establish goals, identify, and solve problems to increase efficiency in this work unit and the organization as a whole. ${ }^{21}$

It is worth mentioning that interaction is the base so that nursing care practice in critical care is implemented and nursing care can be provided; therefore, communication is essential. ${ }^{11}$ When communication problems occur, they directly affect this practice, since they are reflected by nursing care actions. Therefore, appropriate communication among the nursing team matters to patient safety, being essential for the effectiveness of the planning for the use of equipment.

Violation also occurs regarding alarms, when nurses disconnect them during care to reduce the effects caused by the overload of noise on the team, as Nurses 5 and 6 report regarding situations of inappropriate trigger of alarms. These violations bring risks, as described in the field diary of this research, in which the team does not identify a significant alteration in blood pressure levels due to the deliberate reduction in the alarm's volume, with consequent forgetfulness in restoring its initial volume.

This result is ratified by data of incidents associated with patient safety recorded in a base of French notification. In the review of records related to anesthesiology and critical care in 2005 and 2006, such problem is one of the causes of incidents involving equipment categorized as severe. During a period of two years, 197 victims of severe incidents were identified, in which human errors were the main cause. The disconnection or late response to alarms due to the lack of understanding of their function was a common situation. ${ }^{4}$

A systematic literature review that found evidence about the behavior of nurses regarding clinical alarms showed that this behavior is not linear, including the alteration of parameters at the beginning of the shift up to their neglecting. ${ }^{22}$

The concern with behaviors regarding clinical alarms is present in an international organization's publication in the safety field, which presents the greatest potential dangers associated with the use of technologies. Alarms were considered of great relevance in 2013, since they accounted for 80 deaths and 13 permanent damages reported in a record base, in a specific period of this year. Alarms fatigue is a factor mentioned, in which professionals become desensitized or distracted to alarms. ${ }^{7}$

This alarms fatigue's phenomenon occurs with a great number of alarms, which produce sensorial overload and desensitization of the team to their urgency. Consequently, this phenomenon affects clinically relevant alarms through behaviors of nurses such as ignoring, silencing, disabling. ${ }^{23}$ This became clear when researchers measured the stimulus-response time of a coronary unit's team to alarms of multi-parameter monitors. More than $60 \%$ of alarms were considered fatigued (with response higher than 10 minutes) and less than 20\% were attended to within five minutes. ${ }^{23}$

In a second evaluation of the stimulus-response time of the team to alarms triggered by the monitor during invasive blood pressure monitoring, 60 hours of observation were carried out during the day shift, of behaviors of 37 professionals working in the ICU regarding invasive blood pressure alarms. Seventy-six alarms were recorded, of which 21 were attended to with average response time of 2 minutes and 45 seconds. The remaining 55 alarms were defined as fatigued by the authors, because they sounded for more than 10 minutes without response from profissionais. ${ }^{24}$

Therefore, with regard to violations, understanding the social context is important to understand motivations that led to the violation behavior. This calls attention to organizational culture and the behavior of those who are involved. ${ }^{9}$ In this research, this behavior is shown when nurses qualify the occurrence of alarms, for example: "they are very annoying"; "they are too much". These adjectives indicate that the inadvertent trigger of alarms without clinical significance affects professionals and leads to violation behavior.

In the context of this study, it can be observed that the sensorial overload caused by the accumulation of alarms might be one of the factors leading to the occurrence of routine violation and consequent adverse events. Another possible factor according to studies is the difficulty in interpreting alarms due to the lack of understanding of the technological language, which leads to their disconnection.

Based on these results, it is worth mentioning that the safety approach in contemporaneity substitutes the perspective of guilt by the systemic thinking, which recognizes that humans are susceptible to errors, and to prevent them, safe systems that identify their failures must be established before they cause damages. ${ }^{10}$ 
The model that has been widely used in this systemic logic is the James Reason's Swiss Cheese Model, which emphasizes that the focus of error analysis in health care is not only the error at the end, but also the underlying conditions that made it possible. Based on this, defense barriers of the system must be considered to prevent that holes of the cheese (called latent conditions) line up and let the error pass through. ${ }^{10}$

Under this view, the understanding of the violations' motivations based on the analysis of behaviors of nurses, which is the aim of this study, contributes to the implementation of these prevention barriers, with a focus on the change of behavior and system design. This implies the establishment of a safety culture, with strategies that lead individuals to worry about potential risks and real failures from the use of equipment.

Establishing a safe environment means a strong and proactive organizational commitment with safety, with the aim of improving care quality and maintaining a safe environment of patient care, with reduction of preventable errors. ${ }^{25}$ Therefore, recommendations have been made in an attempt to contribute to the reflection on these strategies for promoting a safety culture..$^{26-27}$

Researchers provided an illustration when systematizing recommendations given by 91 nursing professionals about patient safety in ICUs. The recommendations were categorized: in the specific context of the unit, highlighting recommendations for organizational learning and continuous improvement, with emphasis on the undertaking of training/education, with the handling of equipment as one of the themes of interest; and for the improvement of communication among team, management, and work shifts. In the hospital level, recommendations were associated with the support of the hospital management, improving the amount, quality, and maintenance of the equipment. ${ }^{27}$

\section{CONCLUSION}

Taking as reference the problem of incidents with equipment that compromises patient safety in ICUs, the results achieved highlight the role of violations in the occurrence of these incidents and their implications for adverse events.

In the practice of nurses, the research found routine violations that involve battery charging of devices and checking on their functioning before use, as well as the disconnection and reduction of clinical alarms' volume. These violations produce situations of absence of equipment in the unit, nonidentification of clinical complications, and delay of therapeutic conducts.

One of the strategies that is recommended based on such results is the adoption of a checklist for verification of the functioning of devices before their use, especially in intra-hospital transport, to improve communication among the team. Another is the daily checking of alarms according to the individualized condition of each patient, in an attempt to reduce the number of false alarms and situations of reduction of the volume and disconnection of alarms. Furthermore, it is worth mentioning the importance of the use of principles of engineering of human factors in the selection of the equipment, with the aim of reducing the number of devices with problems and consequent fatigue of alarms, in addition to continuous education for better understanding the meaning of alarms.

Finally, it is important to note that professional, organizational, and cultural factors influence the behavior of the nursing team. Therefore, integrating professionals in the management of their communication, technical proficiency, decision making, interpersonal relationship, and situational awareness is paramount, with the aim of minimizing adverse events involving equipment. The present study presented limitations, since the observation was restricted to the day shift, which reduced the number of participants and the comprehensiveness of the results.

\section{REFERENCES}

1. Reis CT, Martins M, Laguardia J. A segurança do paciente como dimensão da qualidade do cuidado de saúde - um olhar sobre a literatura. Ciênc. saúde coletiva. 2013 Jul; 18(7): 2029-36.

2. Ministério da Saúde (BR), Agência Nacional de Vigilância Sanitária. Assistência Segura: uma reflexão teórica aplicada à prática. $1^{\mathrm{a}}$ ed. Brasília: Ministério da Saúde; 2013. 168p.

3. Ministério da Saúde, (BR). Secretaria de Ciência, Tecnologia e Insumos Estratégicos. Política Nacional de Gestão de Tecnologias em Saúde. $1^{a}$ ed. Brasília: Ministério da Saúde; 2011.48 p.

4. Beydon L, Ledenmat PY, Soltner C, Lebreton F, Hardin $\mathrm{V}$, Benhamou D, et al. Adverse events with medical devices in anesthesia and intensive care unit patients recorded in the French safety database in 2005-2006. Anesthesiology. 2010 Feb; 112(2): 364 -72.

5. Mattox E. Medical devices and patient safety. Crit Care Nurse. 2012 Aug; 32: 60-8.

6. Bourgain JL, Coisel Y, Kern D, Nouette-Gaulain K, Panczer M. What are the main "machine dysfunctions" to know? Ann Fr Anesth Reanim. 2014; 33 (7-8):466-71. 
7. ECRI Institute. Know the health technology hazards that pose possible patient risk. OR Manager. 2014; 30(2): -4 .

8. Fairbanks RJ, Wears RL. Hazards with medical devices: the role of design. Ann Emerg Med. 2008 Nov; 52: 519-21.

9. Reason J. Understanding adverse events: human factors. Qual Health Care. 1995; 4:80-89.

10. Reason J. Human errors: models and management. BMJ; 2000; 320:768-70.

11. Silva RC, Ferreira MA. The practice of intensive care nursing: alliance among technique, technology and humanization. Rev Esc Enferm USP. 2013 Dec; 47(6):1325-32.

12. Browne $M$, Cook P. Inappropriate trust in technology: implications for critical care nurses. Nursing in Critical Care. 2011 Mar-Apr; 16(2):92-8.

13. Cassidy J, Smith A, Arnot-Smith J. Critical incident reports concerning anaesthetic equipment: analysis of the UK National Reporting and Learning System (NRLS) data from 2006-2008. Anaesthesia. 2011; 66(10):879-88.

14. Almeida ACG, Neves ALD, Souza CLB, Garcia JH, Lopes JL, Barros ALBL. Intra-hospital transport of critically ill adult patients: complications related to staff, equipment and physiological factors. Acta Paul Enferm. 2012 May-Jun; 25(3): 471-6.

15. Silva R, Amante LN. Checklist for the intrahospital transport of patients admitted to the Intensive Care Unit. Texto Contexto Enferm. 2015 Abr-Jun; 24(2): 539-47.

16. Souza LM, Ramos MF, Becker ESS, Meirelles LCS, Monteiro SAO. Adherence to the five moments for hand hygiene among intensive care professionals. Rev Gaúcha Enferm. 2015 Dec; 36(4): 21-8.

17. Bathke J, Cunico PA, Maziero ECS, Cauduro FLF, Sarquis LMM, Cruz EDA. Infrastructure and adherence to hand hygiene: challenges to patient safety. Rev Gaúcha Enferm. 2013 Jun; 34(2):78-85.
18. Correa CRP, Cardoso Júnior MM. Análise de classificação dos fatores humanos nos acidentes industriais. Produção. 2007 Jan-Abr; 17(1):186-98.

19. Abraham J, Kannampallil T, Patel B, Almoosa K, Patel VL. Ensuring patient safety in care transitions: an empirical evaluation of a Handoff Intervention Tool. AMMIA Annu Symp Proc. 2012 Nov; 2012:17-26.

20. Blouin AS. Improving hand-off communications. Journal of Nursing Care Quality. 2011 Apr-Jun; 26(2):97-100.

21. Camelo SHH. Professional competences of nurse to work in Intensive Care Units: an integrative review. Rev. Latino-Am. Enfermagem; 2012 Jan-Fev; 20(1):192-200.

22. Galo ARL, Diogo CAS, Cipriano DN, Araújo I, Martins JMB, Cunha LDM. Comportamentos dos enfermeiros perante os alarmes clínicos em unidades de cuidados intensivos: uma revisão integrativa. Rev Enf Ref. 2013 Dez; 3(11):105-12.

23. Bridi AC, Silva RCL, Farias CCP, Franco AS, Santos VLQ. Tempo estímulo-resposta da equipe de saúde aos alarmes de monitorização na terapia intensiva: implicações para a segurança do paciente grave. Rev Bras Ter Intensiva. 2014 Jan-Mar; 26(1):28-35.

24. Perghera AK, Silva RCL. Stimulus-response time to invasive blood pressure alarms: implications for the safety of critical-care patients. Rev Gaúcha Enferm. 2014 Jun; 35(2):135-41.

25. Rossi PJ, Edmiston Jr CE. Patient safety in the critical care environment. Surg Clin North Am. 2012; 92(6):1369-86.

26. Tomazoni A, Rocha PK, Kusahara DM, Souza AIJ, MacedoTR. Evaluation of the patient safety culture in neonatal intensive care. Texto Contexto Enferm. 2015 Jan-Mar; 24(1): 161-9.

27. Mello JF, Barbosa SFF. Patient safety culture in intensive care: nursing contributions. Text Context Nursing. 2013 Out-Dez; 22(4):1124-33. 